\title{
Design of Classroom Energy Saving Monitoring System Based on Zigbee Technology
}

\author{
Jie Huang \\ College of Mechanical and Electronic Engineering, Hezhou University, Hezhou, China, 542899 \\ huangjie0773@163.com
}

Keywords: Zigbee; Classroom energy saving; Monitoring system; Wireless sensor

\begin{abstract}
To achieve the purpose of saving energy for the classroom, it designs and implements a classroom energy saving monitoring system based on Zigbee technology. The system includes the classroom monitoring node, the terminal node, the router, the coordinator and the monitoring PC. The system can control the light and the fan in the classroom according to the number of people in the classroom, the intensity and the temperature of the classroom. It also has the function of Zigbee network fault detection. The classroom monitoring node can be remote management and monitoring by the PC through the Zigbee network. According to the actual needs, it can choose and set up the work mode and the networking mode. It mainly introduces the hardware design and software design of the system and made a test to the system. The system has the advantages of flexible networking, good energy saving and high cost performance.
\end{abstract}

\section{Introduction}

With the development of society, more and more schools have been concerned about the energy saving of the classroom. In all kinds of schools, there is a serious waste of classroom use of electricity. In the classroom energy saving monitoring system, each classroom monitoring node usually uses the serial port line or other bus to communicate with the monitoring center. The system wiring trouble, at the same time to the expansion of the system and the cascade is not convenient. The classroom energy saving monitoring system is usually installed in the classroom door on both sides of the infrared device to detect and count the number of people in the classroom. When there are many people walk in or out of the classroom at the same time, the system can not accurately detect and count the number of people .The energy saving effect of the system is affected. In order to overcome the shortcomings of existing classroom energy saving monitoring system, this paper designs and implements a classroom energy saving monitoring and control system based on Zigbee technology.

\section{System Hardware Design}

The system hardware design includes the overall structure of the system design, classroom monitoring node hardware design, router hardware design and coordinator hardware design.

Overall System Structure. Zigbee network supports three kinds of network structure, the star structure, the network structure and the tree structure. Tree network structure is adopted in this design. The overall structure of the system is shown in Fig. 1. The system consists of classroom monitoring node, terminal node, router, coordinator and monitor PC. 


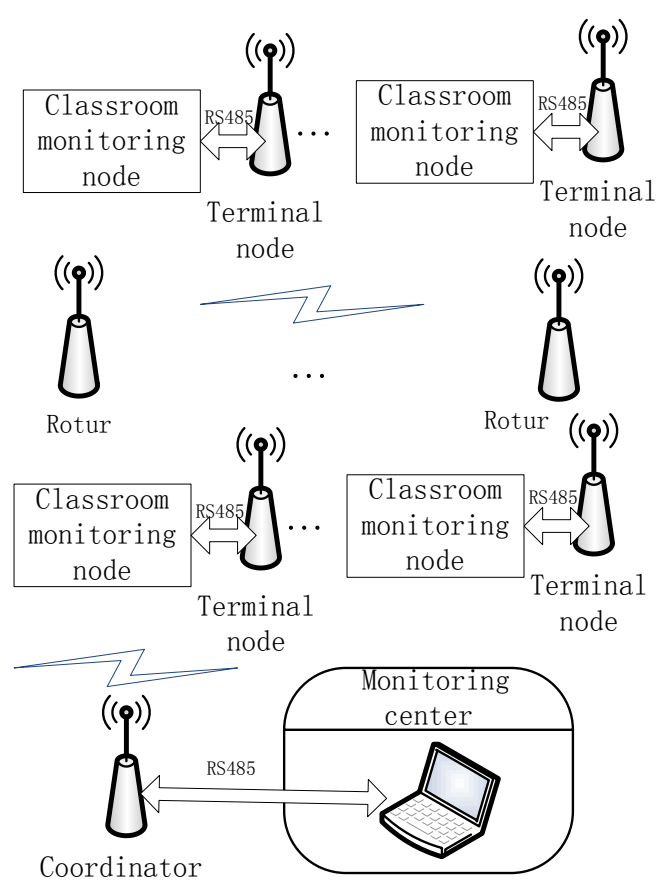

Figure 1. Overall system structure

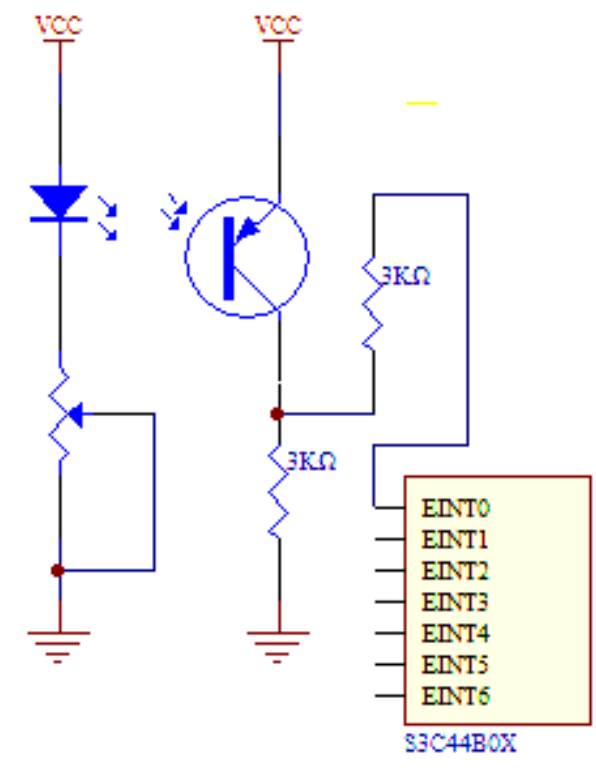

Figure 3. Infrared transmitting and receiving detecting circuit

The classroom monitoring node is connected with the terminal node through the serial port. Terminal node, router and coordinator communicate via Zigbee wireless network. The coordinator is connected with the monitor PC machine through the serial port. Terminal node, router and coordinator are all using CC2530 chip.

Hardware Design of Classroom Monitoring Node. The hardware structure of the monitoring node in the classroom is shown in Fig. 2. The system hardware consists of S3C44B0X microprocessor, infrared transmitting tube, infrared receiving tube, light intensity sensor, lamp control module and fan control module. Infrared transmitting tube and infrared receiving tube are respectively installed outside and inside the door of the classroom. The infrared receiving tube is connected with the interrupt port of the S3C44B0X microprocessor. System through the analysis of the two infrared receiving tube to produce the interruption of the order to determine whether someone walked into the classroom or out of the classroom. Infrared transmitting tube and infrared receiving tube are respectively arranged at the top end and the bottom end of the classroom door. According to the actual average shoulder width and one door of the classroom to set up and install multi infrared transmitting tube and infrared receiving tube. The system is used to detect and count the number of people entering or coming out of the classroom by the infrared transmitting tube and infrared receiving tube installed on the top and bottom of the classroom door. Infrared transmitting tube and infrared receiving tube circuit is shown in Fig. 3. The infrared sensor is used to detect whether there is someone in the classroom. Temperature sensor is used to detect the temperature in the classroom. The light intensity sensor module is used to detect the light intensity in the classroom. 


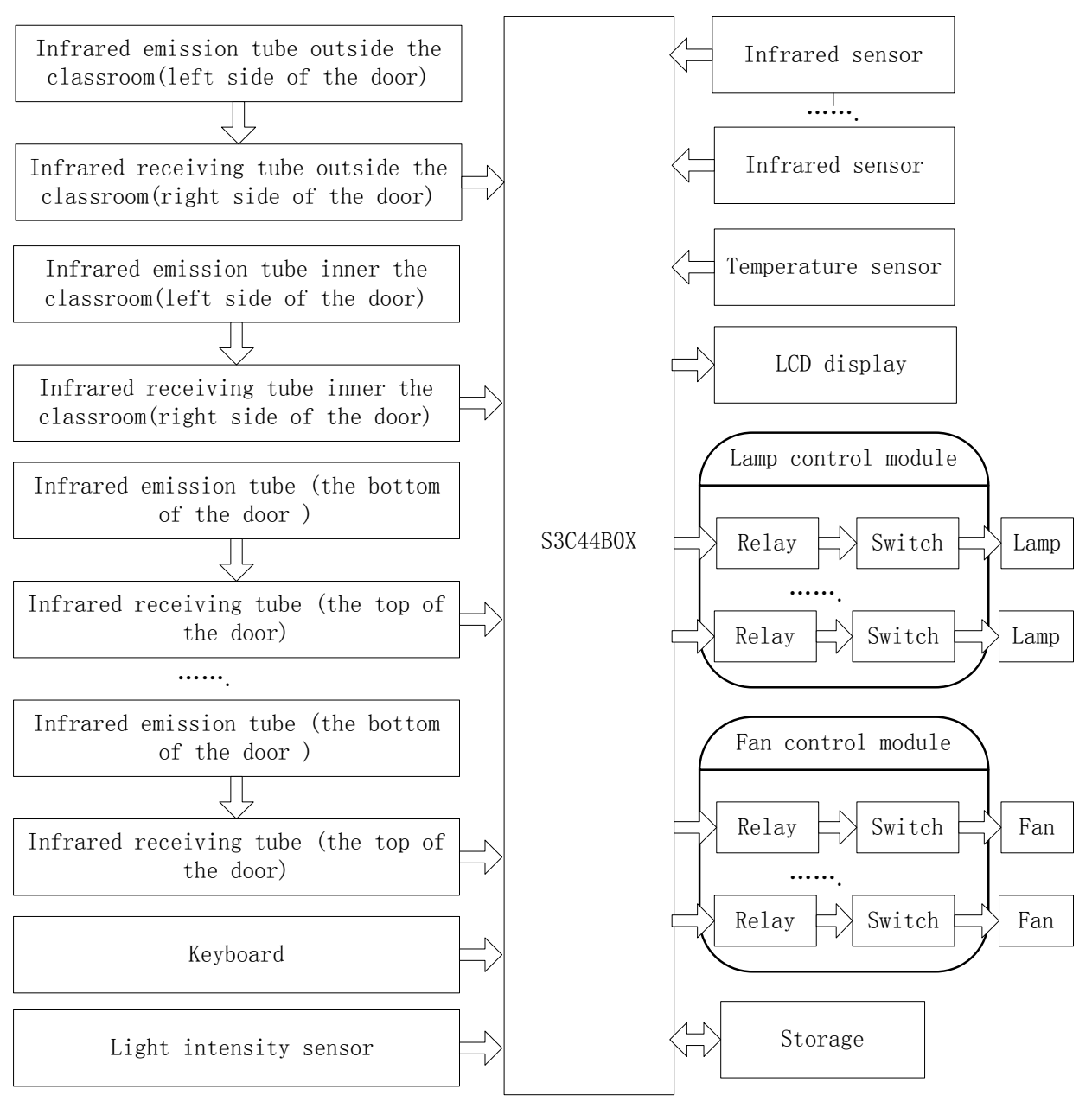

Figure 2. Hardware structure block diagram of classroom monitoring node

\section{System Software Design}

The system software design includes the program design of the classroom monitoring node, the design of the communication protocol and the program design of the monitoring PC.

Monitoring PC Machine Programming. The monitor PC machine uses C\# language programming. By monitoring the monitoring interface of PC machine, the monitoring data can be viewed in real time. The monitoring interface of the PC machine can control the lighting and the fans in the classroom. At the same time, it can also set up the working mode of each classroom monitoring node through the monitoring interface. Monitor PC program flow chart as shown in Fig. 4.

Design of Program and Communication Protocol for Classroom Monitoring Node. Classroom monitoring node uses $\mathrm{C}$ language programming. Classroom monitoring node programming module includes the number of detection and statistics module, keyboard module, light intensity and temperature detection module, lamp control module and fan control module. The program flow chart of the classroom monitoring node is shown in Fig. 5. 


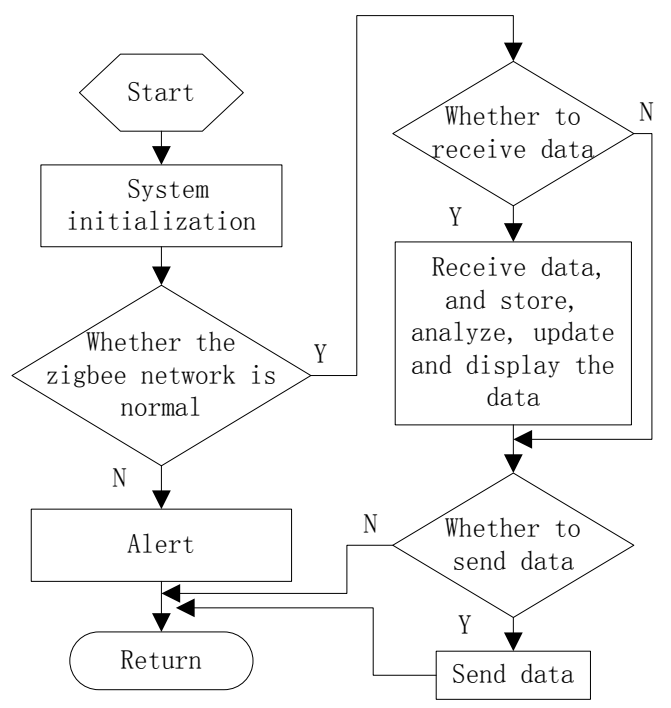

Figure 4. Monitor PC program flow chart

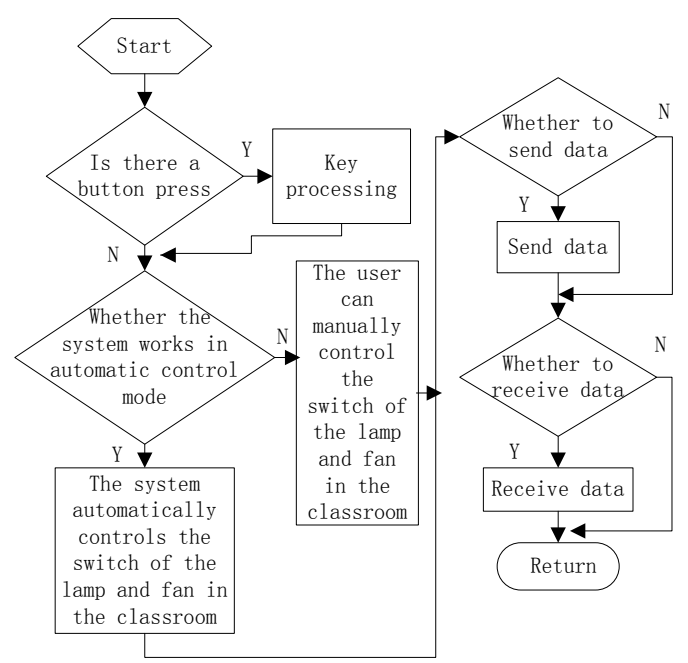

Figure 5. Program flow chart of classroom monitoring node

The classroom monitoring node can communicate with the monitoring PC machine through the Zigbee network. The communication protocols are shown in Table 1.

Table 1 Data communication protocol

\begin{tabular}{c|c|c|c|c|c|c|c}
\hline $\begin{array}{c}\text { Data } \\
\text { header }\end{array}$ & Address & $\begin{array}{c}\text { Operation } \\
\text { type }\end{array}$ & $\begin{array}{c}\text { Data } \\
\text { length }\end{array}$ & $\begin{array}{c}\text { Equipment } \\
\text { number }\end{array}$ & Data & $\begin{array}{c}\text { Check } \\
\text { code }\end{array}$ & $\begin{array}{c}\text { End } \\
\text { symbol }\end{array}$ \\
\hline 1 bytes & 2 bytes & 1 bytes & 1 bytes & $1 \sim 10$ bytes & 1 bytes & 1 bytes & 1 bytes \\
\hline
\end{tabular}

\section{System Test}

According to the design requirements of the system, the system is installed in a teaching building. In the teaching building of the 1 floor and the 2 floor and the 3 floor were installed 6 classroom monitoring nodes and 1 router. In the teaching building, a total of 18 monitoring nodes and 3 routers are installed. Coordinator and monitoring PC installed on the 2 floor of the teaching building. The test data of the system are shown in Table 2 .

Table 2 System test data

\begin{tabular}{c|c|c|c|c|c}
\hline Working mode & $\begin{array}{c}\text { Number of } \\
\text { people in the } \\
\text { classroom }\end{array}$ & $\begin{array}{c}\text { Light } \\
\text { intensity }\end{array}$ & Temperature & $\begin{array}{c}\text { The number of } \\
\text { lights on }\end{array}$ & $\begin{array}{c}\text { The number of } \\
\text { fans on }\end{array}$ \\
\hline $\begin{array}{c}\text { Automatic } \\
\text { control } \\
\text { operation mode }\end{array}$ & 0 & $20(\operatorname{lux})$ & $28\left({ }^{\circ} \mathrm{C}\right)$ & 0 & 0 \\
\cline { 2 - 6 } & 15 & $300(\operatorname{lux})$ & $32\left({ }^{\circ} \mathrm{C}\right)$ & 0 & 2 \\
\hline $\begin{array}{c}\text { Manual control } \\
\text { mode }\end{array}$ & 15 & $30(\operatorname{lux})$ & $35\left({ }^{\circ} \mathrm{C}\right)$ & 4 & 5 \\
\hline
\end{tabular}

\section{Conclusions}

In this paper, we design a classroom energy saving monitoring system based on Zigbee technology. The system can accurately detect and count the number of people in the classroom. Classroom monitoring node and monitoring PC through the Zigbee network for communication. Monitoring 
PC through Zigbee network for remote management and monitoring of classroom monitoring nodes. The system can control the lamp and fan in the classroom according to the number of people, light intensity, temperature and working mode. The system has the characteristics of high statistical precision and flexible networking and good energy saving effect. The system has good application prospects.

\section{References}

[1] Y.L. Zhang, X.P. Zhou and S.X. Zhu: Manufacturing Automation, Vol. 34 (2012) No.4, p.103. (In Chinese)

[2] W.F. Jiang, Q.N. Huang, B.W. Lu and S.F. Lu: Electronic Technology, Vol.26 (2013) No.10, p.44. (In Chinese)

[3] G.X. Liang and T.C. Yuan: Journal of Yangtze University, Vol.34 (2014) No.11, p.85.

[4] H.N. An, J.Y. Jia, L. Zhang and J. Xu: Journal of Guilin University of Electronic Technology, Vol.26 (2014) No.3, p.11. (In Chinese)

[5] Y. Zhou: Information Security and Technology, Vol.20 (2011) No.6, p.84. (In Chinese)

[6] G. Yi: Science and Technology Information, Vol.20 (2012) No.8, p.120. (In Chinese)

[7] X.Q. Wang, Y.J. Ou and N.L. Huang: Design and Implementation of ZigBee Wireless Sensor Network (Chemical Industry Press, Chinese 2012), p.56.

[8] L.M. Sun, J.Z. Li, Y. Chen and H.S. Zhu: Wireless Sensor Network (Tsinghua University press, Chinese 2005), p.85.

[9] J.Z. Du and H. Liu: ZigBee Technical Principle and Actual Combat (Mechanical Industry Press, Chinese 2015), p.132.

[10]Z. Jiang and D. Liu: ZigBee Technology and Practical Training Course (Tsinghua University press, Chinese 2014), p.68. 